\title{
Urban Water Pricing
}

\section{Hugh Sibly}

A water crisis looming in some Australian cities. In Sydney it is currently feared that without significant rainfall the city will run out of water within a few years. In the short term water restrictions have been implemented. Public attention has focussed mainly on technological solutions to the shortage. In Sydney there is debate over whether the water network should be expanded using either recycling or desalination plants. Similar issues are arising in other cities. The use of efficient pricing to ration available water resources, however, has received little attention. In contrast a number of water authorities have championed the use of increasing block tariff (IBT) as a means of conserving water. This paper considers the merits of these pricing reforms.

In Sydney, as in most jurisdictions, the method of retail pricing of water has varied over time. Prior to 1993-94 the then Sydney Water Board adopted a form of IBT. Under IBTs the water provider sets a number of tiers of consumption levels. A low volumetric rate is set in the lowest consumption tier (tier 1) with the rate increasing in subsequent tiers. Prior to 1988-89, Sydney households were given a free allocation of water (that is, tier 1 had a zero volumetric rate). This was replaced by a three tier IBT from 1990-91 until 1992-93 (Sydney Water Board, 1994) and by a two-part tariff in 1993-94 which continued to apply until June 2005. A two-part tariff consists a fixed annual access fee (the fixed charge) and a single volumetric charge which is applied to all consumption. The nominal volumetric rate was $65 \mathrm{c} / \mathrm{kl}$ in $1993-94$ and had increased to $1.013 \$ / \mathrm{kl}$ by $2004-05$. An IBT was re-introduced for 2005-06 and is to apply until at least June 2009.

Urban water is priced differently to other goods. At times of shortages notably droughts - restrictions have been used to control consumption. In contrast, consumers are accustomed to significant variation in the price of virtually all other goods in response to supply side shocks. The recent history of oil prices is a good example. It is often argued that water is unique and should not be priced like other goods. This, as discussed below, is the underlying argument for the use of IBTs - a pricing mechanism rarely used outside the urban water industry.

Implementation of IBTs is possible only because the use of a fixed network to deliver water allows water authorities to tag customers' consumption. IBTs cannot be used without tagging of customers. For example, suppose service stations sought to implement an IBT, say charge $\$ 1$ per litre of petrol up to 20 litres (tier 1) and then $\$ 2$ for each additional litre (tier 2). The likely customer response would be to purchase no more than 20 litres at a time. Thus, the IBT would be ineffective as no customer would purchase petrol in tier 2 .

A network is used to distribute water to urban residents because it is the least cost method of doing so. However, should the concomitant capability of providers

Hugh Sibly is a senior lecturer in the. School of Economics University of Tasmania 
to measure customers' consumption levels be used in implementing IBTs? The economics literature demonstrates that a two-part tariff is the efficient way to price goods delivered by a network (see Carlton and Perloff, 2005:664-9; Sibly, 2005). The key requirement for economic (allocative) efficiency is that the volumetric charge should equal the opportunity cost of water. The volumetric charge has to be flexible in the face of changing cost and demand conditions. In particular, the charge should rise in periods when water is relatively scarce, or when it expected to be relatively scarce. This paper compares the implications of adopting an efficient two-part tariff with those of adopting IBTs and argues that an efficient two-part tariff is better than IBTs in terms of fairness, efficiency and conservation.

Recent developments in Sydney's urban water supply provide a useful setting for the discussion. Although the states use different methods to regulate and manage their urban water supplies, Sydney's problems are the best documented and, at the time of writing, seem the most acute. Other states are referred to when appropriate. Edwards (2005) considers related issues with the implementation of IBTs in Melbourne and is critical of their introduction in that jurisdiction.

The data on storage levels shows that in 1994-95 Sydney storages were, on average, at 62 per cent of capacity, while in 2000-01 they were on average at 90 per cent of capacity. The seeds of the current water crisis can be traced to 2002 . Storage was approximately 80 per cent in late 2001 , but had fallen to 60 per cent by early 2003 . On 5 June 2005 storage was at 39 per cent of capacity. The current concern on storage levels arises because Sydney's storages hold, when full, less than 4 years supply at current consumption rates.

Figure 1: Sydney Urban Water

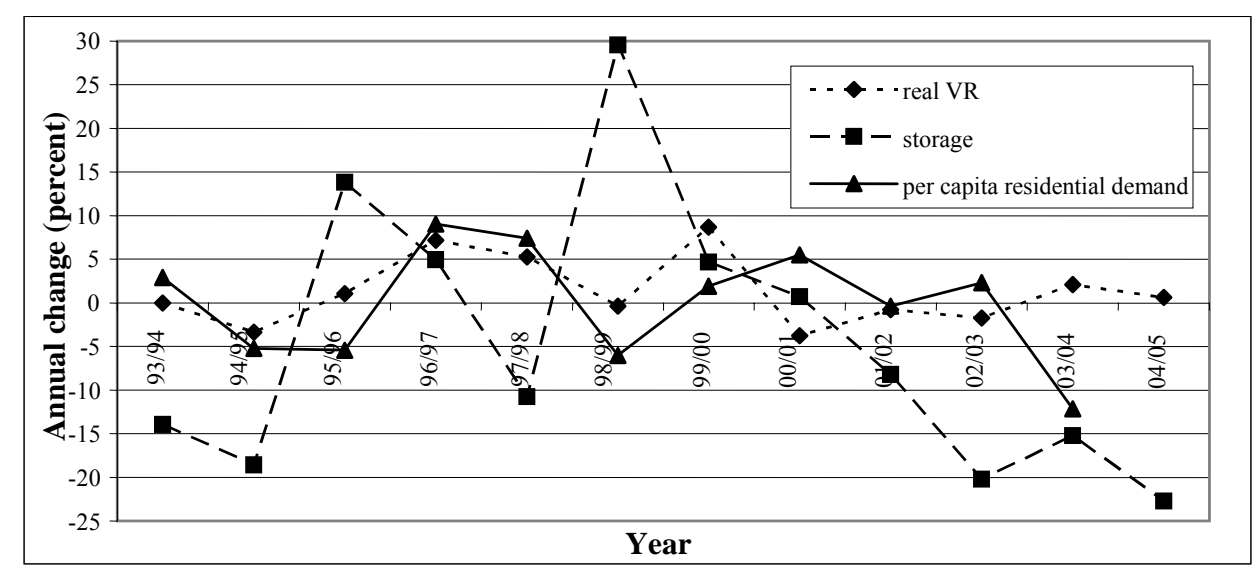

Source: Data provided by Sydney Water, Sydney Catchment Authority.

Figure 1 shows the annual percentage change of available water as a fraction of total system capacity over the last 11 years. The striking feature of this series is its wide variation across years, which reflects the underlying variation in the average annual storage levels of the Sydney water catchments. Figure 1 also shows the growth rate in Sydney's average metered residential consumption. Up 
to 2003 changes in consumption appear to move in the opposite direction to the changes in storage. This pattern is consistent with the demand for water, particularly for outdoor use, being inversely related to rainfall. The fall in average metered residential consumption since 2003 reflects the imposition of increasingly strict restrictions affecting outdoor water use.

The market response to a reduction in supply would be an increase in the price per unit, which in the case of urban water is the volumetric rate set by water regulators. In NSW the regulator is the Independent Pricing and Regulatory Tribunal of NSW (IPART). The growth in the real volumetric rate is also shown in Figure 1. There is no apparent relationship between changes in available storage and the volumetric rate suggesting that the rate has not played a material role in managing demand at times of water shortage. The volumetric rate increases reflect IPART's move away from property based fixed charges toward the implementation of a two-part tariff in the wake of National Competition Policy (NCP) guidelines for 'consumption based pricing' of urban water.

Following the NCP guidelines, NSW, Queensland, Tasmania and Victoria adopted two-part tariffs. However, concerns over increased water scarcity led NSW and Victoria to abandon two-part tariffs with a single volumetric rate and adopt IBTs. This move is presented as a fair and popular response to the water crisis. In NSW, an IPART survey found that 63 per cent of respondents believed IBTs were fairer than the (then) current two-part tariff. The Victorian Government's white paper states that IBTs are 'widely regarded as the fairest and most effective way to price water for conservation'. Both SA and WA have had IBTs in place for some time. The SA Government Committee Water Proofing Adelaide (2004:32) stated that a 'tiered pricing system is considered by some as a fair and effective way of reinforcing the need for conservation...'.

The Council of Australian Governments (COAG, 2004) National Water Initiative (NWI) calls for best practice in water pricing and 'improved pricing for metropolitan water'. Although there is no clear statement of what is best practice in urban water pricing, it is argued in this paper that IBTs are inferior to two-part tariffs. Furthermore, they are inflexible in the face of the erratic nature of water availability in Australia. (Boland and Whittington, 2000, de-bunk the arguments in support of IBTs in an international context.) The apparent support for IBTs arises both from a confusion on the appropriate level of the volumetric rate in a two-part tariff and from a political response against raising the cost of water.

This paper uses economic analysis to clarify these issues and argue that twopart tariffs are the best pricing mechanism. However careful attention must be paid to the setting of the volumetric rate. Specifically, in contrast to the setting of IBTs, the volumetric rate needs to be adjusted to current and expected water availability. Section 2 of this paper discusses efficient pricing methodology, with emphasis on the efficient volumetric rate. Section 3 considers how the methodology to determine the present volumetric rate is different to that required to achieve efficiency. Section 4 considers the impact on efficiency of the use of IBTs. Section 5 discusses implications of the paper's analysis. 


\section{Economic Efficiency and Pricing}

This section uses a simplified economic framework to derive efficient pricing by urban water authority. The framework is not intended to capture every detail of the operations of an urban water network. It is, however, a useful representation of the salient features of a hypothetical water network that identifies underlying efficient pricing principles, particularly the determinants of the efficient volumetric rate. The model assumes a network of fixed capacity. It also assumes there is no alternative use (for example agricultural use) for water flowing into the network and that waste water is released into the sea (so it has no further use). These assumptions avoid introducing complications of non-urban uses of water, which have no material impact on the pricing principles. This scenario is not necessarily unrealistic. For instance, it might broadly represent Sydney if no capacity augmentation (for example, recycling or desalination) is pursued.

Figure 2: Efficient Pricing Over Two Periods

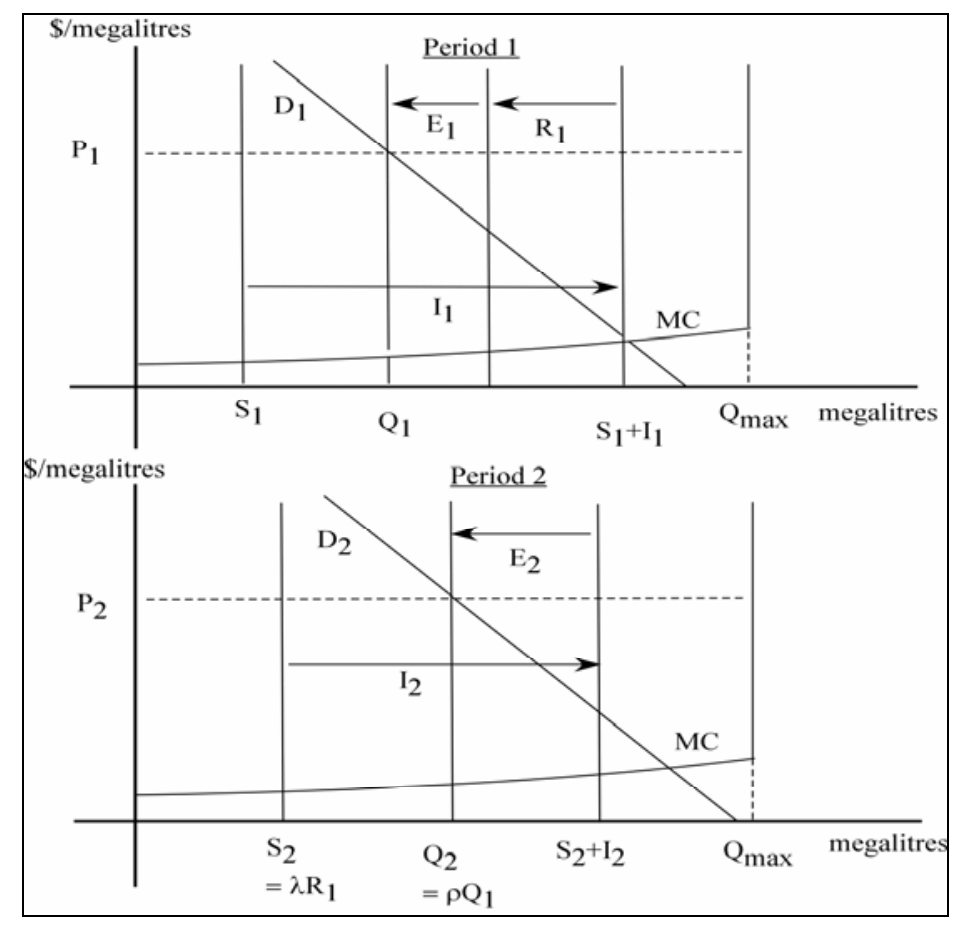

A two period analysis is used to describe the principles for efficient pricing (see Figure 2). Period 1 represents the present and period two the 'future'. Water volume is shown on the horizontal axis and the volumetric rate on the vertical axis. The maximum capacity of the network in both periods is $\mathrm{Q}_{\max }$. $\mathrm{MC}$ is the short run marginal cost curve at output levels below $\mathrm{Q}_{\max }$ and represents the cost to the water provider of supplying an additional $\mathrm{kl}$ of water at each production level. Demand in period 1 is $D_{1}$, while expected demand in period 2 is $D_{2}$. 
It is assumed that there are no capacity constraints in the network. The only constraint is availability of water. Specifically the network has the capability of delivering more water than is available. It is assumed that in period 1 there is an existing water storage level of $S_{1}$ and rainfall causes an inflow of $I_{1}$. The total quantity of water available in period 1 is thus $S_{1}+I_{1}$. Expected inflow in period 2 is $\mathrm{I}_{2}$. It is increasingly recognised that a certain fraction of available water in a catchment must be retained in order to maintain the integrity of the ecosystem. Assume that water authorities decide that a volume of water, $E_{i}$, is retained in each period to support the environment. Furthermore, a volume, $\mathrm{R}_{1}$, is retained in period 1 for use in period 2. That leaves an amount $Q_{1}$ to be consumed in period 1. Similar allocations must be made in period 2 (although it is assumed no water is retained in period 2 as it is the last period). Of the water retained in period 1, there is assumed to be a factional loss of $1-\delta$, so that $S_{2}=\delta R_{1}$.

The available water is allocated across periods on the basis of that available in period 1 and that expected to be available in period 2. The expected volume in period 2 is equal to the sum of storage and the expected inflow, less environmental flows $\left(\mathrm{S}_{2}+\mathrm{I}_{2}-\mathrm{E}_{2}\right)$. A formal derivation of the efficient allocation of quantity across periods (or equivalently the storage level) is beyond the scope of this paper. However, it can be assumed that the usual influences on efficient inter-temporal allocation apply. Thus it is assumed that the efficient allocation satisfies $Q_{2}=\rho Q_{1}$, where $\rho$ depends on the rate of time preference, the rate of population growth, technology efficiency improvements in water use and the rate of water lost in storage $\delta$. For example, an increase in the rate of population growth would see an increase in $\rho$, and thus the size of $Q_{2}$ relative to $Q_{1}$. Similarly an improvement in the technology of water use, such as dual flush toilets, reduces $\rho$.

The efficient volumetric rate generates an efficient inter-temporal allocation. In particular, the efficient volumetric rate is the greater of the market clearing rate in that period or MC. This ensures that the volumetric rate is equal to the opportunity cost of water. As shown in Figure 1, when water availability is low, the efficient volumetric rate clears the market. The gap between the volumetric rate and $\mathrm{MC}$ represents the scarcity value of water. Having made this observation, the efficient response to a change in environmental conditions can be determined. For example, a decrease in current rainfall reduces the current inflow - this has the effect of decreasing the availability of water, thus it is efficient for both $\mathrm{Q}_{1}$ and $\mathrm{Q}_{2}$ to fall. This results in an increase in the efficient volumetric rate in both periods. Similarly the anticipation of a drought in period 2 reduces $\mathrm{I}_{2}$ and thus water availability in period 2. The efficient response increases storage in period 1, reducing $\mathrm{Q}_{1}$. Again, the efficient volumetric rate in both periods increases.

The key conclusion from this analysis is that the efficient volumetric rate should reflect water current and expected availability of urban water. With improvements in long range weather forecasting, meteorological analysis can provide increasingly accurate predictions of seasonal rainfall patterns. Hydrologists can use this information to predict future water availability, which should then be reflected in the volumetric rate. Such a scheme has been suggested as a way of increasing crop yields (Naylor et al, 2002). An increased probability 
of drought (or continuation of drought) should see a rise in the current volumetric rate. Similarly an increase in the environmental allocation should see an increase in the volumetric rate. In cities that are growing, the volumetric rate should also reflect the increased demand caused by population growth.

National competition policy requires government-owned businesses to satisfy competitive neutrality (gain no special advantages from government ownership). Specifically, water authorities should not be subsidised from general government revenue. This implies that they should be regulated to give a normal economic rate of return. They must cover all their costs, including the cost of capital. Because infrastructure is the most significant cost to urban water authorities the revenue raised by the efficient volumetric rate is unlikely to be sufficient to cover the operating costs. However a two-part tariff, consisting of a fixed access charge and the efficient volumetric rate, can be used to achieve both economic efficiency and satisfy this revenue requirement. This is possible because the fixed access charge does not affect water consumption nor does it significantly affect disposable income. The appropriate fixed charge in the two-part tariff is thus set to ensure the water provider's revenue is just sufficient to cover its costs.

Equity considerations are often used to oppose two-part tariffs, particularly if the volumetric rate is perceived to be high. While efficiency requires a volumetric rate equal to the opportunity cost of water, it does not require that the fixed charge be equal across consumers. Thus equity issues can be addressed by varying the fixed charge levied on different classes of consumers. Disadvantaged consumers (as determined by government social policy) could pay a lower fixed charge with water authorities receiving commensurate compensation from the government either in direct payments, or by the government (as owner) accepting a lower than market rate of return from the authority.

\section{Pricing Methodology}

The implementation of NCP has seen a movement toward consumption based pricing. IPART(2004:6) considers that ideally the volumetric rate should be set efficiently. How the efficient volumetric rate should be determined has been controversial even at times of plentiful supply. In Figure 2, plentiful supply of water would occur when $\mathrm{S}_{1}+\mathrm{I}_{1}$ and $\mathrm{S}_{2}+\mathrm{I}_{2}$ are both greater than $\mathrm{Q}_{\max }$. Many academic writers, including Hirschliefer et al (1960), Darr et al (1976), Ng (1987), and King and Maddock (1996) have argued for 'short run marginal cost (SRMC) pricing' when water is plentiful. SRMC is the measure of marginal cost when capacity is fixed. Under SRMC pricing the volumetric rate should be set to the level where the demand curve intersects the MC curve. However, IPART and other Australian water regulators argue that long run marginal cost (LRMC) of supply is the efficient volumetric rate. This is consistent with some overseas thinking. The consulting firm London Economics (1997), and subsequently the UK's Office for Water Services, have argued that LRMC is the efficient volumetric rate. The American Water Works Association (2000:120) states that 
'economic theory suggests that water rates be set equal to long run marginal cost to ensure efficient allocation of water services'.

In economic texts, LRMC is the measure of marginal cost when capacity can be varied incrementally. It is the cost of an extra litre of water when all factors of production (including capital) are varied optimally (Call and Holahan, 1983:25862). LRMC pricing is efficient in those circumstances. In other words, LRMC is the efficient price only when capital is adjusted to its optimal level. But as textbooks note in those circumstances, short- and long-run marginal cost coincide.

Divergences of opinion between academics and regulators on efficient rates seem curious, given that the textbook analysis of marginal cost is well understood by the economics profession. This controversy appears to stem from observations that investment decisions of water utilities are 'lumpy' rather than incremental (Hirschliefer et al:1960) and subsequent interpretation of the analysis of marginal cost by Turvey $(1971$; 1976) who argues that investment decisions by public enterprise are best thought of in a dynamic context. An incremental increase in the growth of output can be accommodated by incrementally advancing the utility's investment plans. Thus, at any one time the availability of infrastructure may be thought of as varying incrementally in a textbook 'long run' fashion. Pricing and investment decisions should go hand in hand, with the efficient outcome being the combination of a short run pricing rule and optimal investment rule (1971:74). In Turvey's work the timing of investment in infrastructure is varied so that a volumetric rate equal to LRMC is sufficient to utilise existing capacity. Thus in each period, under the optimal investment plan, MC=LRMC.

Turvey's argument is both ingenious and subtle. However there are two problems with its application to current Australian circumstances. It assumes that the optimal investment rule is in place, and capacity may be fully utilised when required. Neither of these requirements is usually true for Australian water utilities. First, many prospective infrastructure developments face significant uncertainty and political controversy. With such planning difficulties, projects are likely to be delayed or even cancelled. Even if this were not so, the investment decisions and pricing decisions are made by different authorities. In Sydney's case, the Sydney Catchment Authority is charged with infrastructure development, while IPART regulates retail prices. This discourages coordination of pricing and investment decisions. It is hard to see how the optimal investment rule could in practice be implemented in a manner envisaged by Turvey. Second, and most notably, the erratic nature of rainfall patterns in Australia means that it is quite common for water utilities to be unable to fully utilise their network's capacity.

The impact of water authorities imposing LRMC pricing in current (water shortage) circumstances can be seen using Figure 2. An increase in capital in period 2 increases $\mathrm{I}_{2}$. (Assume the expansion is a desalination plant that does not rely on rainfall to operate.) Capital should be increased in period 2 until the (market clearing) volumetric rate is equal to LRMC. Thus, with this expansion in capital, the volumetric rate would be lower than it would otherwise have been. However, if for some reason the expansion does not take place, the efficient volumetric rate is $\mathrm{p}_{2}$, not LRMC. In this case LRMC underprices water. 
Observe that an expansion of capacity in period 2 enables less water to be stored in period 1. Thus $\mathrm{R}_{1}$ could be decreased and the volumetric rate in period 1 lowered. However, such a strategy requires that the additional capacity be available in period 2, otherwise a shortage in period 2 ensues. Again, the reliance on LRMC pricing is likely to lead to an inefficiently low volumetric rate if for some reason new capacity is delayed or not installed.

Under current Australian institutional arrangements, it is thus reasonable to assume that investment plans are independent of the pricing decision. In this case LRMC does not give a good approximation to the efficient volumetric rate, even with stable availability of water and demand growth. With erratic availability of water, the price stability provided by LRMC pricing works against efficient water allocation. In periods of drought LRMC significantly underprices water because it fails to reflect opportunity cost. At times of high storage levels and low demand water is overpriced (price is greater than MC). In addition, calculation of LRMC is difficult in practice. It is therefore simpler and more efficient to determine the volumetric rate using the methodology discussed in the previous section.

\section{Effect of IBTs}

In 2005 IPART moved to a two tier IBT to regulate the volumetric rate charged by Sydney Water. The regulated volumetric rates have been set until June 2009 . These are shown in Table 1. IPART (2004) sets out the reasoning for adopting this particular two tier IBT. The first tier of the volumetric rate is intended to equal LRMC. Thus the volumetric rate in tier 1 is roughly the existing volumetric rate adjusted for inflation. The volumetric rate in tier 2 is intended to 'send strong conservation signals', and thus, as shown in Table 1, is moving over time towards being 1.5 times the tier 1 volumetric rate. Tier 1 applies to consumption up to $400 \mathrm{kl}$ per annum. The setting of the tier 1 boundary is to allow "non-discretionary use' to be paid for at the tier 1 volumetric rate. It should be noted that the average consumption of a 5 occupant household is $370 \mathrm{kl}$ per annum and 6 occupant house 408kl per annum (see Table 2).

Table 1: Sydney Water's Regulated Volumetric Rate

\begin{tabular}{|c|c|c|c|c|}
\hline & to $30 / 06 / 2006$ & 1/07/06 - 30/06/07 & $\begin{array}{l}1 / 07 / 07-30 / 06 / 08 \\
k L\end{array}$ & $1 / 07 / 08-30 / 06 / 09$ \\
\hline Tier 1 & 1.20 & $1.23 \times(1+\Delta \mathrm{CPI} 1)$ & $1.26 \times(1+\Delta \mathrm{CPI} 2)$ & $1.31 \times(1+\Delta \mathrm{CPI})$ \\
\hline Tier 2 & 1.48 & $1.59 \times(1+\Delta$ CPI1 $)$ & $1.72 \times(1+\Delta \mathrm{CPI} 2)$ & $1.85 \times(1+\Delta \mathrm{CPI} 3)$ \\
\hline Tier $2 /$ Tier 1 & 1.23 & 1.30 & 1.37 & 1.41 \\
\hline
\end{tabular}

Source: IPART (2005)

The efficiency of IBTs is assessed using Figure 3. Under an IBT each connection pays a volumetric rate $t_{1}$ per $k l$ for consumption up to $\mathrm{T} k \mathrm{l}$, then a rate of $t_{2}$ per $\mathrm{kl}$ for consumption beyond that level. Suppose, for simplicity, there are only two types of customers. One type has the low demand $\mathrm{D}_{\mathrm{L}}$ and the other has 
the high demand $\mathrm{D}_{\mathrm{H}}$. Under the IBT low demand consumers consume $\mathrm{q}_{\mathrm{L}}$ and high demand consumers consume $\mathrm{q}_{\mathrm{H}}$.

Table 2: Average Annual Household Consumption

\begin{tabular}{l|cccccc}
\hline Household size (no. of occupants) & 1 & 2 & 3 & 4 & 5 & 6 \\
Consumption per occupant (kl) & 142 & 114 & 89 & 76 & 74 & 68 \\
\hline Source: IPART (2004:15)
\end{tabular}

Figure 3: Increasing Block Tariffs

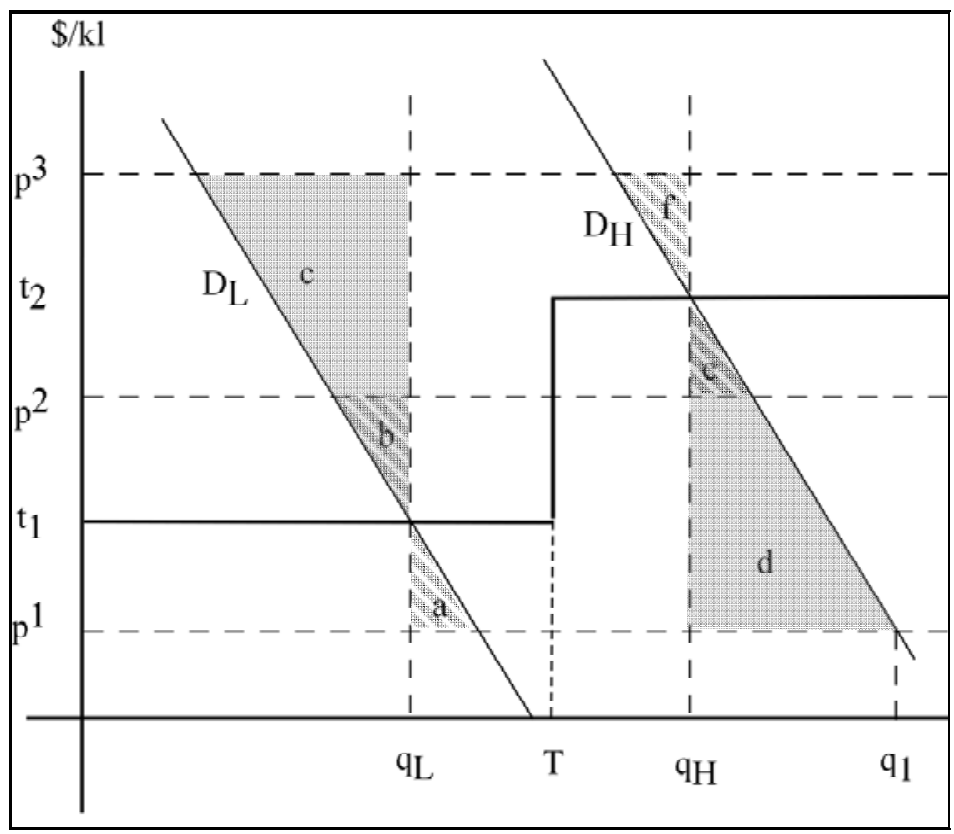

Figure 3 shows that the inefficiency of an IBT depends on the efficient volumetric rate in that period. The efficient rate represents the opportunity cost of water. The loss of economic efficiency of IBTs can be measured by the deadweight loss (DWL), which represents the loss of potential net benefit of an inefficient price. When water is abundant, suppose the efficient volumetric rate is $\mathrm{p}_{1}$. If the volumetric rate is $\mathrm{p}_{1}$ the high demand consumer uses $\mathrm{q}_{1}$. The loss of net benefit (or DWL) is measured by the difference between the height of the demand curve and the opportunity cost of water $\mathrm{p}_{1}$. In this case DWL associated with the consumption of high demand consumer is $\mathrm{e}+\mathrm{d}$. Similarly low demand consumers have a DWL equal to the area a. If water becomes less available, the efficient volumetric rate would rise. Consider the efficient volumetric rate $\mathrm{p}_{2}$, which lies between $t_{1}$ and $t_{2}$. In this case the DWL associated with a low demand consumer is $b$ while that of high demand consumer is e. Finally if the efficient volumetric 
rate rises to $\mathrm{p}_{3}$ the DWL from low demand consumers is $b+c$ and that from high consumers is $\mathrm{f}$. This analysis indicates that an IBT can never be efficient when there are heterogeneous customer demands. At every efficient level of the volumetric rate there is a DWL created by an IBT.

A common argument is that IBTs do not create inefficiencies because the IBT reflects the increasing marginal costs of the water provider (or increasing scarcity of water). This argument is spurious because each individual user has a negligible effect on total consumption and therefore on the marginal cost of the provider. However, a variant of this argument is valid when there are common demands and thus demand curves shift simultaneously. For example, consider seasonal shifts in demand. Figure 3 can be adapted to consider this circumstance. Suppose now DL represents the common winter water demand and DH the common summer water demand. Suppose that $t_{1}$ and $t_{2}$ are the efficient volumetric rate in winter and summer respectively. In this case IBTs result in an efficient allocation of urban water. However, for this result to hold demand must be homogeneous and there must be no annual variation in the efficient seasonal volumetric rate. Neither of these conditions holds in practice. Furthermore, the same outcome could be achieved more simply with a two-part tariff with an efficient volumetric rate.

The focus in the literature on seasonal prices derives from European and North American applications, where water utilities face a capacity constraint at peak times. Thus seasonal prices are directly related to peak load pricing theory issues. However this literature is not of central importance to current Australian applications where the concern is erratic variation in water availability. IBTs (or any form of peak load pricing) do nothing to address shortages that arise because of this variation, primarily because they do not vary with availability. An IBT that fully utilises capacity at times of high availability does not also ration water at times of low availability. In spite of popular perception, IBTs are not flexible enough to solve the water crisis and also be efficient when the drought breaks.

Water authorities have noted the inefficiency of IBT. IPART (2004:20) notes that in its proposal 'tier 2 charges would not be chosen for economic efficiency reasons ... there could be merit in using it to send an additional signal to those residential customers who use a high volume of water, to encourage them to reduce their discretionary use of water'. This ignores economic reasoning, in particular that water consumption, discretionary or otherwise, confers a benefit on households. There is no reason to believe that the 401th $\mathrm{kl}$ confers less benefit on a 7 person household than the 300th kl confers on a one person household. In fact, this example demonstrates how an IBT leaves unexploited gains to trade between households. If the two households were next door to each other, they could gain by running a hose from the 1 person household to the 7 person household!

Penalising high use consumers under IBTs is thus justified on equity and conservation, rather than efficiency grounds. However, the assumption that high users are necessarily wasteful is contradicted by the data in Table 2 on average consumption per occupant for households in the Sydney, Blue Mountains and Illawarra regions for 2003. The figures show that consumption per occupant declines as household size increases. This is consistent with economies of scale in 
water use. Indeed the consumption per occupant for the 6 person household is less than half that of the single person household. Yet IBTs will cause the larger household to face a higher marginal rate than that of the smaller one. This is neither fair, nor serves conservation.

\section{Discussion}

Economists teach first year undergraduate students that monopolies set inefficiently high prices, and that price controls can mitigate this exercise of monopoly power. The NWI (COAG, 2004:66) calls for upper bound (maximum) pricing to avoid water providers making monopoly rents. However this regulatory focus on the natural monopoly aspect of urban water authorities has deflected attention from the efficient price of water itself. In major metropolitan areas of Australia the problem is not that water is overpriced because of monopoly power, but rather that its volumetric rate is systematically underpriced.

The sources of the current underpricing are manifold. In its implementation NCP has focussed more on cost recovery and technical efficiency than allocative efficiency. This reflected the concerns of providers and regulators, who have focussed most of their attentions on cost recovery, and how its achievement affects various household types. In fairness, regulators have also concerned themselves with allocative efficiency issues, but the methodology used to determine the efficient volumetric rate is not appropriate for Australian conditions.

However, as is often the case with government business enterprises, the problem in achieving allocative efficiency is the political dimension to water pricing. Both the LRMC and IBT methods are relatively politically appealing. As argued above, a volumetric rate based on the LRMC methodology is both stable and, in effect, low. Boland and Whittington (2000:234) argue that IBT allows water utilities 'to deliver cheap water to the middle- and upper-income groups while appearing to serve the poor'. In Australian, IBTs have the effect of insulating typical consumers from facing the cost of decreased water availability.

IBTs are easy to justify politically, because their implementation can be blamed on water hogs, who are punished by their introduction. But the real culprit for the water shortage is climatic variability, and the way in which the country's water authorities plan for, and respond to, it. The implementation of IBTs is an attempt to allow water users to avoid confronting the implications of variability in water availability, and it allows many users escape the cost of their actions.

IBTs thus seem to have an irresistible appeal to regulators. Providing a 'free allocation' to consumers has been used frequently in the past by water providers. Sydney and Melbourne are now returning to the use of IBTs. IPART (2004:24) recommends IBT instead of two-part tariff because:

1. vulnerable customers face a higher bill under two-part tariffs;

2. two-part tariffs send a weaker conservation signal to high water users; and

3. two-part tariffs do not distinguish between discretionary and nondiscretionary use. 
These arguments are commonly cited to support the use of IBTs, and are misleading for the following reasons:

1. IBTs do not provide targeted welfare, and thus do not necessarily deliver low bills to vulnerable consumers. For example, large, low income families are likely to face the higher tier 2 tariff notwithstanding that on average they consume less water per person than smaller households. From a welfare and efficiency point of view it would be superior to introduce a two-part tariff with an efficient volumetric rate. Then a rebate of the fixed charge can be paid to vulnerable consumers. Such a rebate can be well targeted and flexible; for example, it could vary with a consumer's income and number of dependents.

2. Two-part tariffs send only an inefficiently weak conservation signal when the volumetric rate is set below the efficient level. IBTs necessarily send the wrong signals to some consumers.

3. Non-discretionary use is a poorly defined concept. For example, the use of toilets would normally be classed as non-discretionary. Yet replacement of a single flush toilet with a dual flush system can significantly reduce this 'nondiscretionary' use. However defined, the annual non-discretionary use is well below the cut-off point for current tier 1 tariffs. Under these IBTs the volumetric rate for most 'non-discretionary' use is the tier 1 rate.

Invoking the concept of non-discretionary demand as a means of allocating water is problematic from an economic perspective. The distinction between discretionary and non-discretionary demand presumably relates to differences in the willingness to pay for different uses of water. For example, water used for showers (non-discretionary) would have a higher marginal benefit than water used to wash the car (discretionary). However, only consumers can identify their demand for the duration and frequency of given activities. An efficient volumetric rate allows consumers to make this choice. Water authorities targeting, and then restricting, activities declared 'non-discretionary' removes this choice from households, and thus may lead to an inefficient allocation of water across uses.

The concept of discretionary use has enabled water authorities to avoid raising the volumetric rate to the efficient level. Rather they have introduced restrictions on certain types of use and introduced IBTs. By attempting to restrict supply this way, they have attempted to smooth the volumetric rate rather than (as is efficient) water quantity. Such an approach is politically appealing, as it gives the appearance of reducing real water bills at the same time as restricting usage. However it is inefficient, and will be ineffective if available water is not increased.

IBTs not only send the wrong price signals to consumers, but to the water providers themselves. IBTs (usually) undervalue the water sold in the first tier, and thus provide insufficient incentive to expand supply. Without identifying the market clearing volumetric rate, it is unclear whether an expansion of capacity is warranted. This issue will become increasingly important if, as foreshadowed by 
NCP, it is decided that some water networks will allow private providers to supply water. An underpriced volumetric rate set by a government owned provider would appear to contravene the NCP requirement of competitive neutrality.

Adopting a volumetric rate that reflects current and expected water availability will incur some additional costs. For example, frequent changes in the volumetric rate may require water meters to be read more frequently. It would also be necessary to advertise changes in the volumetric rate. However, these costs are likely to be small when compared to the benefits. The adoption of an efficient two-part tariff would see storage levels drop more slowly at times of drought. This would see a reduced need for additional storage capacity to cover consumption over periods of low rainfall. Furthermore, there would be less need to rely on water restrictions at times of drought (see Sibly 2005). Indeed the reduced requirement to advertise water restrictions would, to some extent, offset the costs of advertising changes to the volumetric rate.

As water shortages grow in Australia's metropolitan areas, the importance of using efficient pricing increases. The key reform required is the implementation of an efficient volumetric rate, which takes account of the erratic Australian rainfall patterns. It is the rate that clears the market for the available water and, importantly, reflects the expected availability of water. The fixed charge satisfies the residual revenue requirement. Equity concerns can be addressed by rebates of the fixed charge to disadvantaged groups. Unfortunately, many water authorities have abandoned the implementation of two-part tariffs and are proposing IBTs, which are not flexible in the face of changing availability of water. Rather they give the illusion of delivering efficiency, equity and conservation. This paper demonstrates that, in reality, they provide these things imperfectly.

\section{References}

American Water Works Association, (2000), Principles of Water Rates, Fees and Charges, AWWA Manual M1, $5^{\text {th }}$ Edition, Denver.

Boland, J. and Whittington, D. (2000), 'The Political Economy of Water Tariff Design in Developing Countries: Increasing Block Tariffs versus Uniform Price with Rebate', pp. 215-236 in A. Dinar (ed), The Political Economy of Water Reform, Oxford University Press, New York.

Call, S. and W. Holahan (1983), Microeconomics, $2^{\text {nd }}$ Edition, Wadsworth, Belmont, Cal.

Carlton, D. and Perloff, J. (2000), Modern Industrial Organisation, $3^{\text {rd }}$ Edition, Addison Wesley, Reading, Mass.

Council of Australian Governments, (2004), 'Intergovernmental Agreement on a National Water Initiative’, June, available at http://www.coag.gov.au/meetings/250604/.

Darr, P., S. Feldman and C. Kamen (1976), The Demand for Urban Water, Martinus Nijhoff, Leiden.

Edwards, G. (2005), 'Demand Management for Melbourne's Water', paper presented to Economic Society of Australia Conference of Economists, University of Melbourne, September. 
Hirshleifer, J., J. De Haven and J. Milliman (1960), Water Supply: Economics, Technology, and Policy, University of Chicago Press, Chicago.

Independent Pricing and Regulatory Tribunal of NSW (2003), 'Investigation into the Price Structure to Reduce Demand for Water in the Sydney Basin', Issues Paper, December.

Independent Pricing and Regulatory Tribunal NSW (2004), Investigation into the Price Structure to Reduce Demand for Water in the Sydney Basin, Final Report, July.

Independent Pricing and Regulatory Tribunal NSW (2005), 'Sydney Water Corporation, Hunter Water Corporation, Sydney Catchment Authority: Prices of Water Supply, Wastewater and Stormwater Services: Final Determination', Sydney, September.

King, S. and R. Maddock (1996), Unlocking the Infrastructure: The Reform of Public Utilities in Australia, Allen and Unwin, Sydney.

London Economics, (1997), 'Water Pricing: The Importance of Long Run Marginal Cost', Report prepared for the Office of Water Services, February.

Naylor, R., W. Falcon, N. Wada and D. Rochberg (2002), 'Using El Nino - Southern Oscillation Climate Data to Improve Food Policy Planning in Indonesia', Bulletin of Indonesian Economic Studies 38(1):75-91.

Ng, Y-K. (1987), 'Equity, Efficiency and Financial Viability: Public Utility Pricing with Special Reference to Water Supply', Australian Economic Review 79:21-35.

Productivity Commission, (1992), Water Resources and Waste Water Disposal, Canberra.

Productivity Commission (2004), 'Review of National Competition Policy Reforms', Discussion Draft, Canberra, October.

Sibly, H. (2006), 'Efficient Urban Water Pricing', Australian Economic Review, forthcoming.

Sydney Water Board, (1994), Demand Management in the Water Board, Sydney, August.

Turvey, R. (1971), Economic Analysis and Public Enterprise, Allen and Unwin, London.

Turvey, R. (1976), 'Analyzing the Marginal Cost of Water Supply', Land Economics 52(2):158-68.

Water Proofing Adelaide, (2004), 'A Thirst for Change — The Water Proofing Adelaide Draft Strategy', Adelaide.

I would like to thank two anonymous referees and editors Ross McLeod, Franco Papandrea and Graeme Wells for very useful suggestions on an earlier draft of this paper. All errors remain my responsibility. 